\title{
Análisis de contenido de la programación sensacionalista pública española: propuesta de cuestionario como medidor de los hábitos de la audiencia audiovisual
}

Content Analysis of Sensationalist Spanish Public Television: A Proposal of a Questionnaire to Measure Audience Habits

\author{
Patricia de-Casas-Moreno \\ Consejo Técnico Revista Comunicar (Universidad de Huelva)
}

Pablo Maraver-López

Becario FPU (Universidad de Huelva)

\section{Ignacio Aguaded}

Catedrático de Educación, Director del Programa de Doctorado Interuniversitario de Comunicación y Director Grupo Comunicar (Universidad de Huelva)

Fecha de recepción: 1 de octubre de 2015

Fecha de revisión: 19 de enero de 2016

Para citar este artículo: de-Casas-Moreno, P., Maraver-López, P. y Aguaded, I. (2016): Análisis de contenido de la programación sensacionalista pública española: propuesta de cuestionario como medidor de los hábitos de la audiencia audiovisual, Icono 14, volumen (14), pp. 1-23. doi: 10.7195/ri14. v14i1.914 


\section{ARTÍCULOS DE INVESTIGACIÓN}

\section{Resumen}

Uno de los rasgos básicos que definen la Sociedad de la Información es la espectacularización que abarca como espacio narrativo la información de carácter sensacionalista. El principal objetivo de este trabajo es crear y validar un cuestionario como medidor de los hábitos de la audiencia audiovisual. El instrumento ha sido sometido a proceso de validación mediante juicio de expertos. Además, esta investigación se encuentra reforzada por un estudio de análisis de contenido que clarifica y analiza los estereotipos ideológicos representados en los programas de carácter sensacionalista, y más detalladamente en el programa de Televisión Española, "Corazón», a lo largo de 15 emisiones seleccionadas en febrero de 2015. Los resultados obtenidos ayudarán a desarrollar futuras líneas de investigación sobre los estereotipos presentes en la crónica social televisiva, así como a comprender el consumo y la competencia mediática de la sociedad.

Palabras clave: Televisión, sensacionalismo, estereotipos, audiencia, análisis de contenido, cuestionario

\section{Abstract}

One of the core characteristics that define the Information Society is the spectacularization that encompasses the narrative space as sensationalist information. The main objective of this study is to present a proposal original questionnaire to measure television audience habits. The instrument has been subjected to validation process by expert judgment. In addition, this research is reinforced by a content analysis study that clarifies and analyzes the ideological stereotypes represented in sensationalist programs, and in more detail in the program of Spanish Television, "Corazón", over 15 selected issues in February 2015. The results will help to develop future research on stereotypes in television social chronicle and also to understand the consumption and media competence in society.

Key Words: Television, sensationalism, stereotypes, audience, content analysis, questionnaire 


\section{Introducción}

Los medios de comunicación son los encargados de dar a conocer la realidad creando modelos y pautas de conductas que influyen en la identidad social del espectador. De esta manera, la escuela, las amistades, el trabajo, los medios de comunicación e incluso, la familia, son los encargados de transmitir información sobre los distintos roles que desempeña la sociedad (Gila \& Guil, 1999:90-91; Marín, 2012:194-195).

En este contexto, la televisión es conocida como el medio de comunicación por excelencia. La audiencia elige este medio para estar informada de lo que acontece diariamente, primando la existencia de una programación con contenido de calidad $\mathrm{y}$, que a la misma vez, se convierta en el soporte de la creación de la opinión pública. Asimismo, este instrumento informativo está caracterizado por ser el encargado de representar y crear iconos sociales a través de la construcción de la realidad (Gilovich, 1993:88-111; Searle, 1997:93-123; Berger \& Luckmann, 2003: 162-202; March \& Prieto, 2006: 25).

Con la llegada del siglo XXI muchos países han presenciado diversas transformaciones en sus sociedades, precisando nuevas competencias y destrezas para conseguir adaptarse a los medios tecnológicos. Por lo tanto, para comprender la evolución a la que estamos asistiendo es necesario diferenciar dos tipos de alfabetizaciones: por un lado, la alfabetización mediática, concebida como un conjunto de competencias comunicativas basadas en el acceso, el análisis, la evaluación y la transmisión de la comunicación de múltiples formas (Lee, 2010; NAMLE, 2010; Lee \& So: 2013: 138) y, por otro lado, la alfabetización informacional, entendida como la habilidad de acceso, evaluación y uso de la información a través de diferentes fuentes informativas. Hay que destacar que ambos conceptos, aunque parezcan no estar relacionados, mantienen un objetivo común: cultivar la habilidad de las personas para acceder, comprender, utilizar y crear mensajes mediáticos. En este sentido, es inexcusable educar a los televidentes para que posean una mirada crítica a la hora de integrarse en un proceso comunicativo. Por este motivo, se requiere una educación audiovisual que alfabetice a las personas frente a los medios de comunicación (Belmonte \& Guillamón, 2008: 115). 
Muchas son las investigaciones que han indicado que la televisión ha convivido en dos etapas diferentes: la Paleotelevisión y la Neotelevisión (Eco, 1986:200; Imbert, 2008; Gordillo, 2009). Esta última etapa se presenta como un espejo de la realidad, recreando los hábitos cotidianos de los actores y que más tarde, se verán reflejados en los espectadores y en sus pautas de conducta. Los nuevos contenidos del formato televisivo, además de estar caracterizados por el morbo y la intimidad, ofrecen un gran protagonismo a personas conocidas en la crónica social. Sin duda, la nueva realidad se presenta como espectáculo convirtiendo la información generalista en sensacionalista y creando una hiperrealidad televisiva valorada por las emociones humanas con el fin de satisfacer al espectador a través de las imágenes. El consumo incesante de información ha provocado que la sociedad realice la constante búsqueda de su identidad, estableciendo a los medios de comunicación como modeladores para entender qué es socialmente aceptable e identificarse con sus pares (Fuente, Martínez \& Del-Prado, 2014: 56). Tal y como apuntaba Ferrés (1997: 49), «en definitiva, cada vez que la imagen conecta un sentimiento con una realidad, está confiriendo sentido a esa realidad».

Desde comienzos de los años 90, la televisión ha sufrido constantes cambios debido a la fuerte competencia de las grandes empresas de comunicación por captar la máxima audiencia posible. Esta lucha está provocando múltiples permutaciones en la organización y contenidos de los programas, forjándose una mediamorfosis competitiva en los factores de calidad y el impacto de la audiencia, acercándose al concepto de telerrealidad y alejándose de los formatos de carácter informativo o cultural (Cáceres, 2012: 124; Romero-Rodríguez, De Casas-Moreno \& Torres-Toukoumidis, 2015: 32). Además, el concepto que conocemos de servicio público de la televisión ha decaído estrepitosamente debido a la industria comercial, la que consideraba que el servicio público cumplía mejor su función si aumentaba la audiencia televisiva al margen de ofrecer calidad en los formatos e informaciones (Talavera \& Bermejo, 2007: 308).

Por otro lado, existe una preocupación constante en el mundo de la investigación académica por la búsqueda de parámetros de calidad correctos para que prime una programación informativa y de entretenimiento a gusto de los espectadores (Camacho, 2006). Asimismo, la televisión se considera como un instrumento unificador para la actividad económica y concienciador de la cultura de masas, eliminando cualquier vínculo con la realidad objetiva (Imbert, 2004: 71). 
Soler (2005: 309) señala que debido al constante conflicto entre las grandes empresas de comunicación, se están generando programaciones conocidas como «telebasura» y que cada vez ocupan más espacios en las distintas cadenas. Por su parte, Debord (1976), apunta que este fenómeno de la «telebasura» es definido como «no un simple conjunto de imágenes, sino como una relación social entre personas, mediatizadas por imágenes». El autor parte de la justificación que existe para separar al hombre de lo real y la realidad de la imagen. Mientras, Vargas-Llosa (2009: 6) describe la civilización del espectáculo como un mundo donde predomina el entretenimiento, el cual puede producir consecuencias negativas como por ejemplo la banalización de la cultura, la generalización de la frivolidad y la proliferación del periodismo irresponsable. Nos encontramos en una constante revolución multimedia, donde el denominador común según Sartori (2012), es «tele-ver y vídeo-vivir». El acto de tele-ver está cambiando la naturaleza del hombre frente a la televisión, la cual está transformando al homo sapiens en un homo videns influenciado por la fuerza que han cobrado las imágenes audiovisuales.

Desafortunadamente, la televisión se ha convertido en el medio de comunicación más destructivo en cuanto a los conocimientos que transmite a la sociedad. Ésta es la culpable de crear la televisión a su imagen y semejanza a través de la ficción de los hechos, adaptándolos al lenguaje audiovisual y creando tópicos y estereotipos. Este suceso es posible debido al carácter espectacular del medio y el trabajo de algunos profesionales al buscar personajes fácilmente reconocibles para el público. Algunas de las características más significativas de los estereotipos son las siguientes según Galán-Farjado (2006: 59-61):

- Son conceptos compartidos por grupos sobre otros grupos.

- Usan símbolos para transmitir valoraciones.

- La aplicación se dirige a grupos determinados.

- Son difíciles de modificar. 


\section{ARTÍCULOS DE INVESTIGACIÓN}

Atendiendo a la importancia de la televisión como representación de los productos culturales, valores y pautas de conductas adoptadas por la sociedad, debemos conocer la clasificación de estereotipos negativos y positivos. Los estereotipos negativos son aquellos que se generan a partir de un grupo considerado problemático para la sociedad; mientras que por otro lado, los estereotipos positivos son aquellos usados por los grupos dominantes en beneficio de sí mismos (González \& Leal, 2010). Además, la televisión se ha convertido en un reflejo de la sociedad y por ello se representan en ella múltiples estereotipos asignados por la ciudadanía a determinados individuos y colectivos sociales. Estos iconos representativos terminan convirtiéndose en estereotipos debido a la influencia mercantil que mantienen los medios de comunicación en la actualidad. Por lo tanto, el sujeto se convierte en objeto y más tarde en mercancía, induciendo a que se creen valores y antivalores asociados involuntariamente a un individuo o grupo (Romero-Rodríguez, 2014: 102).

Remitiéndonos a estas características, podemos indicar que la mayor parte de los estudios realizados sobre los estereotipos y su influencia a través de la programación audiovisual son negativos, así como las repercusiones sociales que puede provocar.

El proceso de confección de los estereotipos se desarrolla en dos etapas diferentes tal y como apuntan Brown-Givens \& Monahan (2005). Por un lado, la primera etapa es la activación del sistema de creencias personales asociadas a ciertos grupos con determinados estereotipos y, por otro lado, la segunda etapa es la encargada de interpretar la información que percibe el espectador de aquellas ideas relacionadas con los grupos minoritarios.

Actualmente, el público es educado a través de la televisión y la publicidad, favoreciendo a la construcción imaginaria y adquiriendo conocimientos de realidades enmascaradas. A partir de esta idea, podemos matizar que los estereotipos cumplen funciones importantes relacionadas con la subordinación de los grupos estableciéndose una posición fuerte frente al individuo (Amossy \& Herschberg, 2010: 43). En este sentido, el estereotipo se convierte en un instrumento generador de tensión entre las relaciones interpersonales, concibiéndose prejuicios frente a otras personas. 
Es necesario acentuar que es el espectador quien dota a las imágenes de significado, aunque éstas lleven implícitas una manipulación previa. Por lo tanto, serán ellos los encargados de interpretar el mensaje a través de su conciencia crítica y alfabetización mediática. (San Miguel, Fidalgo y Santos, 2012: 194). Por lo consiguiente, la televisión se convierte en la encargada de modelar y crear pautas de conductas a raíz de la emisión de programas basados en el espectáculo. Además, debido al consumo excesivo de los programas de carácter sensacionalista, se generan multitud de estereotipos ideológicos.

Por otro lado, los patrones de la prensa sensacionalista se aplican cada vez más a las noticias de televisión, llegando a espectacularizar a los programas relacionados con la crónica social. La prensa del corazón, también llamada «rosa», es uno de los temas más llamativos dentro del estudio de los medios de comunicación de masas. Al fin y al cabo, se trata de una prensa de consumo fácil que pretende entretener, distraer y promocionar nuevos rostros de la prensa del corazón, famosos o pseudofamosos en muchos casos, que sin explicación ocupan ahora los programas televisivos de máxima audiencia, donde el morbo, el sensacionalismo y la intimidad son las claves del éxito.

Los programas de carácter sensacionalista se han convertido en la principal influencia de la sociedad, gestionando los contenidos y manipulando la realidad en busca de beneficios. En este sentido, es necesario un estudio exhaustivo de los hábitos de la audiencia para conocer de qué forma consumen este tipo de programación. Este análisis es importante tanto para los medios privados, ya sea por el beneficio económico, como para los medios públicos por la otorgación de la legitimidad cultural.

Igualmente, este tipo de programación establece un poderoso aumento en la audiencia, ya que es un tipo de género que se presta a la interactividad entre el emisor y receptor de la información. Además, con la creación de la opinión se desarrollan una serie de variables que perjudican a la sociedad. Los conocidos estereotipos están manifestados en nuestra cultura y, sobre todo, los podemos apreciar en los medios de comunicación. A partir de esta problemática, surge la necesidad de estudiar, investigar y examinar detalladamente esta competencia mediática 


\section{ARTÍCULOS DE INVESTIGACIÓN}

debido a la abundancia de programas cargados de información manipulada y de baja calidad informativa. Autores como Debord (1976), Imbert (2003; 2004) o GonzálezRequena $(1985 ; 1989)$ relatan la información del espectáculo como la culpable de la creación de la opinión y percepción critica inadecuada, ofreciendo posibilidades de cómo consumir la programación de este tipo.

Consecuentemente, para conocer los hábitos de la audiencia se debe realizar un análisis sobre las condiciones sociales del individuo, es decir, un estudio sociodemográfico, que nos ayude a valorar los patrones de conductas. Por lo tanto, antes de ahondar en los hábitos de consumo debemos hacer hincapié en la definición de «hábitos», que no es otra que aquellos modos de actuar adquiridos por la repetición de los actos de una persona. El espectador debe mantener un papel activo frente a los medios de comunicación, sin embargo, esta percepción cambia a la hora de consumirlos según sus necesidades. En este sentido, muchos son los autores que han estudiado la conducta de los individuos a la hora de consumir información (Katz \& Blumler, 1974; Fleur \& Ball-Rokeach, 1982; Tourine 1993; Kubey \& Csikszentmihalyi, 2013) identificando tres recursos de gratificación centrándose en los contenidos, en la exposición y en el contexto. La gratificación a través de los contenidos establece que la mayor parte de la audiencia tiende a elegir el entretenimiento antes que la información. Esto provoca la creciente competencia entre los medios de comunicación por obtener la máxima audiencia, transformando la información en espectáculo. La gratificación por la mera exposición se centra en el estudio de consumir cualquier medio de comunicación, sobre todo la televisión. Y por último, la gratificación como consecuencia del contexto conduce a la hipótesis de que ver televisión constituye para las personas un hábito social.

En definitiva, debido a la creación de los estereotipos a través de los programas de carácter sensacionalista, es necesario afirmar que el lenguaje es tradicionalmente sexista y que además, las representaciones visuales se convierten en modelos de conductas, cada vez más consumidos por la audiencia activa (Acaso, 2006). Sin duda, múltiples son los programas televisivos que acogen contenidos relacionados con el culto al cuerpo femenino, como por ejemplo el programa que hemos elegido para realizar esta investigación, «Corazón» de Televisión Española (TVE), cuya temática está basada en la trayectoria profesional de las figuras de actualidad y acontecimientos 
sociales como bodas, bautizos, incluso divorcios. A raíz de este tipo de programación, el imaginario social se va deconstruyendo y el respeto por el honor y la intimidad de las personas consiguen que la profesión periodística pierda credibilidad.

También, podemos resaltar la capacidad de la audiencia para construir las interpretaciones de los productos culturales presentes en la televisión. El desequilibrio entre la recepción y la emisión del mensaje se puede atribuir a un delicado juego de poderes establecido entre la televisión y los espectadores (Núñez, 2005: 301). Las industrias culturales presentan un modo de producción basado en la transformación de los valores creativos en valores económicos a través del trabajo en cadena, la estandarización y la emisión de productos asequibles para el público masivo. Estas nociones entroncan con la producción de los programas de carácter sensacionalista, interesados en que su contenido llegue a la mayor audiencia posible.

\section{Material y métodos}

El principal objetivo de esta investigación es crear y validar un cuestionario como medidor de los hábitos de la audiencia audiovisual, con el fin de convertir esta herramienta en un instrumento fiable que sirva para evaluar las conductas del espectador en la televisión de carácter sensacionalista para futuras líneas de investigación. De esta manera, este estudio se encuentra reforzado por un análisis de contenido clarificando y analizando los estereotipos ideológicos representados en este tipo de programas, y más detalladamente en el programa de Televisión Española (TVE), «Corazón», a lo largo de 15 emisiones seleccionadas en febrero de 2015. De esta forma, el análisis de contenido se encuentra enfocado en la representación de los estereotipos de las figuras y personajes famosos cuyo fin es corroborar los modelos de conducta de los espectadores frente a los sujetos o actores protagonistas de las emisiones.

\section{a. Participantes}

Para el análisis de los estereotipos, hemos atendido a una muestra de quince emisiones visionadas en el mes de febrero de 2015 del programa de Televisión Española (TVE), «Corazón», con una duración total de 412 minutos y 30 segundos. Por su parte, para la validación del cuestionario y con el fin de medir los 
hábitos de la audiencia, hemos contado con la participación de 6 personas expertas en el ámbito de la educación y la comunicación. Además, el instrumento ha sido cumplimentado por una muestra piloto de 12 sujetos, escogidos tras realizar una entrevista previa y seleccionar a aquellas personas que consumían este programa.

\section{b. Instrumentos}

Para la recogida de los datos cualitativos se ha utilizado el visionado de los diferentes capítulos del programa de televisión «Corazón» de Televisión Española (TVE) y para estudiar el análisis de contenido se ha recurrido al programa informático MAXQDA. Por su parte, los resultados cuantitativos arrojados por el cuestionario fueron tratados y analizados con el programa de análisis de datos SPSS v17.

\section{c. Procedimiento}

Para realizar este estudio se ha empleado la técnica conocida como análisis del discurso a partir de las distintas codificaciones que han sido utilizadas en las transcripciones de las grabaciones de vídeo. El análisis fue organizado en función de categorías analíticas con el fin de perseguir una conceptualización y explicación teórica del texto. Los datos fueron recogidos a partir del análisis de quince emisiones del programa «Corazón» de Televisión Española (TVE). La elección de este programa está basada en su periodicidad diaria, de lunes a domingo, y en la gran tradición que ha mantenido desde sus inicios hasta la actualidad en el desarrollo de la cadena nacional española, TVE 1, gozando siempre de una audiencia estable según los análisis métricos de AGB Nielsen Media Research (2000-15).

El análisis está centrado en la descripción objetiva de los quince programas y de las distintas piezas informativas, conformadas por sus informadores y personajes del mundo de la farándula. El fin de este estudio es describir los estereotipos que se desarrollan en este tipo de emisiones televisivas y, que cada vez, están más cotizadas en las televisiones familiares. 
En la segunda parte del estudio, hemos optado por una vertiente más cuantitativa para construir y validar un cuestionario que nos ayude en futuros trabajos a medir los hábitos de la audiencia respecto al consumo de la programación de carácter sensacionalista. Este cuestionario ha sido diseñado con el objetivo de realizar un estudio comparativo entre la programación de las cadenas públicas y privadas españolas. Por lo tanto, en primer lugar se ha realizado una validación del constructo llevada a cabo por un grupo de 6 personas expertas pertenecientes a materias en educación y comunicación $\mathrm{y}$, por otro lado, se ha realizado una prueba piloto con una muestra de 12 individuos. El coeficiente de fiabilidad del instrumento tras hallar el Alpha de Cronbach es de .735.

\section{Resultados}

Este apartado de resultados, está organizado tratando de dar respuesta a los objetivos planteados en esta investigación. Por un lado, se revelan las soluciones obtenidas tras realizar el análisis de contenido del programa de carácter sensacionalista seleccionado, «Corazón» de TVE 1 y, por otro lado, exponemos y explicamos la validación de nuestra propuesta de cuestionario para estudiar los hábitos de la audiencia en el consumo de este tipo de programas a través de una prueba piloto realizada y la validación de expertos.

\subsection{Análisis de contenido}

Los estereotipos que hemos estudiado en esta investigación están justificados a partir de las siguientes dimensiones con las que se puede categorizar al personaje: clase social, procedencia, profesión y edad. En estos programas han participado un total de 128 periodistas, siendo el $80 \%$ mujeres, además de un total de 350 personajes pertenecientes al mundo de la fama, perteneciendo un $58 \%$ al sexo femenino. En la tabla 1 se despliegan los resultados del análisis de contenido de las quince emisiones en relación a las distintas dimensiones pertenecientes a los estereotipos (Véase Tabla 1). 
12 | Patricia de-Casas-Moreno, Pablo Maraver-López e Ignacio Aguaded

\section{ARTÍCULOS DE INVESTIGACIÓN}

\begin{tabular}{|c|c|c|c|c|c|c|c|c|c|c|c|c|c|c|c|c|c|}
\hline & & 1 & 2 & 3 & 4 & 5 & 6 & 7 & 8 & 9 & 10 & 11 & 12 & 13 & 14 & 15 & Total \\
\hline \multirow{3}{*}{$\begin{array}{l}\text { CLASE SO- } \\
\text { CIAL }\end{array}$} & A & 9 & 5 & 7 & 12 & 14 & 9 & 6 & 9 & 3 & 5 & 8 & 6 & 8 & 7 & 4 & 112 \\
\hline & $M$ & 15 & 18 & 17 & 15 & 10 & 12 & 8 & 10 & 23 & 20 & 16 & 16 & 16 & 19 & 22 & 237 \\
\hline & B & - & - & 1 & - & - & - & - & - & - & - & - & - & - & - & - & 1 \\
\hline \multirow{2}{*}{$\begin{array}{c}\text { PROCEDEN- } \\
\text { CIA }\end{array}$} & $\mathrm{N}$ & 18 & 20 & 19 & 23 & 15 & 15 & 10 & 11 & 22 & 10 & 19 & 19 & 20 & 21 & 19 & 261 \\
\hline & I & 6 & 3 & 6 & 4 & 9 & 6 & 4 & 8 & 4 & 15 & 5 & 3 & 4 & 5 & 7 & 89 \\
\hline \multirow{4}{*}{ EDAD } & 20 & - & 2 & 1 & 3 & 4 & - & 3 & 3 & - & - & - & - & 1 & - & - & 17 \\
\hline & 40 & 16 & 20 & 13 & 19 & 15 & 20 & 11 & 12 & 21 & 22 & 20 & 7 & 21 & 18 & 17 & 252 \\
\hline & 60 & 6 & 1 & 11 & 5 & 5 & 1 & - & 4 & 5 & 3 & 4 & 15 & 2 & 8 & 8 & 78 \\
\hline & $>$ & 2 & - & - & - & - & - & - & - & 1 & - & - & - & - & - & 1 & 4 \\
\hline \multirow{4}{*}{ PROFESIÓN } & $\mathrm{R}$ & 1 & - & - & - & - & - & 1 & - & - & - & - & - & - & - & - & 2 \\
\hline & A & 2 & 2 & 1 & - & 1 & 1 & - & 1 & - & 1 & 2 & 2 & 1 & 1 & 1 & 16 \\
\hline & M & 17 & 21 & 24 & 24 & 22 & 18 & 7 & 15 & 21 & 19 & 19 & 20 & 19 & 19 & 23 & 288 \\
\hline & $\mathrm{F}$ & 4 & - & - & 3 & 1 & 2 & 6 & 3 & 5 & 5 & 3 & - & 4 & 6 & 2 & 44 \\
\hline
\end{tabular}

Tabla 1: Frecuencia sobre los estereotipos

En este sentido, atendiendo a la clase social hay que destacar que la mayoría de los personajes o famosos, que intervienen en este programa, son de clase social media $(68 \%)$, aunque la clase social alta también predomina en un alto rango (32\%). Además, un alto porcentaje de los personajes son de procedencia nacional (75\%), a pesar de que no faltan las figuras internacionales más conocidas de la actualidad.

Por otro lado, en relación a la edad de los personajes, predominan aquellas personas con edades comprendidas entre los 20 y los 40 años (72\%). Se trata de 
figuras mediáticas con gran relevancia en los medios por su popularidad tanto en su vida privada como en su vida profesional. En un segundo peldaño, podemos observar que existe un número elevado de individuos oscilando entre los 40 y 60 años $(22 \%)$, mientras que los menores de 20 años y los mayores de 60 años son congruentemente escasos (6\%).

Finalmente, para conocer la posición social hay que atender a la profesión que desempeña cada uno de los individuos que aparecen en televisión. El grupo de los meritócratas asume un papel vehemente en estas producciones caracterizado por la popularidad que les han ofrecido sus trabajos (modelo, actor, torero, etc). De este modo, dicha clase social irrumpe con 288 menciones $(82,28 \%)$ del un total de 350 presentes en las 203 piezas informativas. El segundo puesto en el ranking lo obtienen los famosos por relación -aquellos que obtienen su notoriedad por relacionarse con personajes públicos- con 44 menciones $(12,57 \%)$, seguidos por la aristocracia y la realeza que en conjunto ocupan 18 menciones $(5,14 \%)$. Como hemos podido comprobar, prevalecen las apariciones de aquellos famosos que emergen constantemente en televisión como son los cantantes, toreros, modelos y diversos meritócratas, que hacen que el espectador capte múltiples ideas y los catalogue según sus declaraciones, historias y las informaciones que se facilitan sobre ellos.

\subsection{Análisis del cuestionario}

En este apartado presentamos los resultados de la creación y validación de un instrumento para medir los hábitos de la audiencia frente a los programas de carácter sensacionalista. El cuestionario está compuesto por un primer apartado relacionado con los datos demográficos y un segundo apartado de preguntas cerradas sobre el consumo televisivo. Finalmente, cuenta con una escala tipo Likert con puntuaciones de 1 a 5, donde 1 significa totalmente en desacuerdo, 2 en desacuerdo, 3 neutral, 4 de acuerdo y 5 totalmente de acuerdo.

El cuestionario está conformado por 33 ítems, abarcando cinco dimensiones que tratan de responder a unos objetivos específicos. Los resultados que se presentan a continuación corresponden al estudio piloto llevado a cabo con el cuestionario que obtiene un coeficiente de fiabilidad Alpha de Cronbach de .735. 


\subsubsection{Análisis de los ítems y dimensiones}

Para detallar los pasos que hemos realizado para la construcción de esta herramienta hay que señalar que en primer lugar, se exhiben los estadísticos descriptivos de los ítems componentes y las puntuaciones totales de las dimensiones, mientras que en segundo lugar, se aporta el análisis de contenido del cuestionario recogido a través del juicio de expertos.

Cabe recordar, que el primer objetivo consiste en analizar los hábitos y tipos de audiencia de programas televisivos para conocer los perfiles individuales. Por lo tanto, se han atendido a los siguientes indicadores en esta dimensión: el consumo de la televisión, los canales/programas consumidos y el uso que se hace de este medio. A continuación, en la tabla 2, se pueden observar las puntuaciones medias y desviaciones típicas de los ítems de esta primera dimensión (Véase Tabla 2).

\begin{tabular}{|l|c|c|}
\hline \multicolumn{1}{|c|}{ ITEMS } & Media & Desv. Típ. \\
\hline $\begin{array}{l}\text { 1. Pienso que la televisión es un medio importante para la sociedad } \\
\text { por su carácter de servicio público informativo }\end{array}$ & 4.25 & .452 \\
\hline 2. La televisión es un medio que uso para estar informado/a & 4.25 & .622 \\
\hline 3. La principal característica de la televisión es entretener & 4.75 & .622 \\
\hline 4. La televisión ofrece un carácter educativo a la sociedad & 3.17 & .577 \\
\hline 5. Consumo adecuadamente este tipo de programas sensacionalistas & 4.00 & .953 \\
\hline TOTAL & 4.08 & .645 \\
\hline
\end{tabular}

Tabla 2: Estadísticos descriptivos de los items componentes y puntuación total de la dimensión 1

Esta dimensión recibe altas puntuaciones ante las afirmaciones planteadas, destacando una puntuación inferior en el ítem 4 sobre el carácter educativo de la televisión. Este ítem presenta una media centrada con un valor próximo al 3. En resumen, la media total es elevada y la desviación típica es sutil en contraste con las puntuaciones totales obtenidas en las dimensiones posteriores. 
La segunda dimensión pretende analizar los contenidos y hábitos en los programas sensacionalistas de canales públicos y privados de España desde la perspectiva de la audiencia. En la siguiente tabla podemos observar las puntuaciones obtenidas por cada ítem para comprenderlas mejor (Véase Tabla 3).

\begin{tabular}{|l|c|c|}
\hline \multicolumn{1}{|c|}{ ITEMS } & Media & Desv. Tip. \\
\hline 6. El canal de TVE 1 procura una buena cobertura informativa & 3.92 & .515 \\
\hline 7. Tele 5 es un canal de televisión de calidad informativa & 2.67 & 1.07 \\
\hline $\begin{array}{l}\text { 8. Consumo este tipo de programas porque informan y educan } \\
\text { 9. Consumo prensa de corazón porque entretiene y es divertida }\end{array}$ & 2.00 & 1.13 \\
\hline $\begin{array}{l}\text { 10. Consumo televisión sensacionalista porque me gusta estar } \\
\text { informado/a de las vidas ajenas }\end{array}$ & 3.92 & 1.16 \\
\hline $\begin{array}{l}\text { 11. El cometido de este tipo de programas es manipular y tergi- } \\
\text { versar la información }\end{array}$ & 4.42 & 1.56 \\
\hline $\begin{array}{l}\text { 12. Cuando consumo estos programas los comento con alguien } \\
\text { Total }\end{array}$ & 2.50 & 1.51 \\
\hline $\begin{array}{l}\text { 13. Estos programas se caracterizan por sensacionalistas y mor- } \\
\text { bosos }\end{array}$ & 4.25 & .754 \\
\hline $\begin{array}{l}\text { 14. Con frecuencia, los derechos humanos son atacados (derecho } \\
\text { de la imagen, derecho de la intimidad, derecho a la libertad de } \\
\text { expresión y derecho a la información }\end{array}$ & 3.92 & .900 \\
\hline $\begin{array}{l}\text { 15. El personaje público está obligado a ofrecer información, } \\
\text { aunque esto signifique violar el derecho de intimidad de las } \\
\text { personas } \\
\text { 16. Los programas de carácter sensacionalista (rosa, de cotilleo }\end{array}$ & 3.42 & .996 \\
\hline
\end{tabular}

Tabla 3: Estadísticos descriptivos de los ítems componentes y puntuación total de la dimensión 2

Las puntuaciones más bajas las recogen los ítems 7, 8, 12 y 15 que versan sobre la calidad informativa, el carácter educativo de los programas sensacionalistas y el papel de los personajes públicos. En general, esta dimensión presenta unas medias más centradas y desviaciones típicas más elevadas. 


\section{ARTÍCULOS DE INVESTIGACIÓN}

El tercer objetivo radica en analizar los discursos televisivos de los programas audiovisuales sensacionalistas de España desde el punto de vista del consumidor. Por lo tanto, en esta dimensión destacan los ítems 18 sobre el grado de credibilidad de los contenidos y el 20 sobre la influencia en las relaciones sociales de las personas, obteniendo un grado de desacuerdo. Asimismo, la puntuación media total está cercana a 3 y la desviación típica es moderada (Véase Tabla 4).

\begin{tabular}{|l|c|c|}
\hline \multicolumn{1}{|c|}{ ITEMS } & Media & Desv. Típ. \\
\hline 17. El lenguaje usado para informar es correcto & 3.25 & .622 \\
\hline $\begin{array}{l}\text { 18. El grado de credibilidad de los contenidos es muy alto } \\
\text { 19. La información transmitida en el programa goza de calidad } \\
\text { informativa }\end{array}$ & 2.50 & 1.17 \\
\hline $\begin{array}{l}\text { 20. A raíz del consumo de la prensa del corazón mi consumo } \\
\text { televisivo y mis relaciones sociales están más influenciadas por } \\
\text { los valores transmitidos en los programas }\end{array}$ & 1.83 & .622 \\
\hline $\begin{array}{l}\text { 21. Los/as periodistas que trabajan en este tipo de periodismo } \\
\text { son una figura mediadora muy importante }\end{array}$ & 3.50 & .937 \\
\hline 22. El discurso televisivo es vulgar y coloquial & 4.00 & .674 \\
\hline TOTAL & 3.22 & .953 \\
\hline
\end{tabular}

Tabla 4: Estadísticos descriptivos de los ítems componentes y puntuación total de la dimensión 3

Para finalizar, el cuarto objetivo trata de descubrir los diferentes estereotipos que existen en los programas sensacionalistas a partir del análisis de contenido y aquellos percibidos por la audiencia. Los indicadores de esta dimensión son la creación de estereotipos y la función social de estos. Por consiguiente, destacan los ítems 29 y 30 por su baja puntuación, aunque son los ítems con mayor desviación típica. Por otro lado, el ítem 26 muestra una puntuación media elevada. Estos resultados podrían estar influenciados por la deseabilidad social de esta dimensión (Véase Tabla 5). 
ARTÍCULOS DE INVESTIGACIÓN

\begin{tabular}{|l|c|c|}
\hline \multicolumn{1}{|c|}{ ITEMS } & Media & Desv. Típ. \\
\hline 23. Los programas sobre farándula generan y crean estereotipos & 3.67 & .651 \\
\hline $\begin{array}{l}\text { 24. Los estereotipos predominantes en este tipo de programación } \\
\text { son sexistas }\end{array}$ & 2.92 & .793 \\
\hline $\begin{array}{l}\text { 25. Otros estereotipos que podemos encontrar en el visionado } \\
\text { audiovisual son raciales y clasistas }\end{array}$ & 2.17 & .835 \\
\hline $\begin{array}{l}\text { 26. Los estereotipos se definen como la imagen o idea aceptada } \\
\text { comúnmente por un grupo o sociedad con carácter inmutable }\end{array}$ & 3.92 & .289 \\
\hline $\begin{array}{l}\text { 27. Los estereotipos representados en televisión cumplen una } \\
\text { importante función en la vida social }\end{array}$ & 2.92 & .669 \\
\hline $\begin{array}{l}\text { 28. El valor de una persona se encuentra en el aspecto físico, tal } \\
\text { y como indican los medios de comunicación }\end{array}$ & 2.42 & .996 \\
\hline 29. Mi persona ideal se identifica con mi famoso/a preferido/a & 1.67 & 1.155 \\
\hline 30. Me identifico con alguno de los protagonistas de los programas & 1.67 & 1.155 \\
\hline \multicolumn{1}{|c|}{ TOTAL } & 2.67 & .818 \\
\hline
\end{tabular}

Tabla 5: Estadísticos descriptivos de los ítems componentes y puntuación total de la dimensión 4

\subsubsection{Validez del cuestionario}

Con el fin de recoger evidencias sobre la validez del instrumento, el cuestionario ha sido sometido a un juicio de expertos siendo evaluado por un total de seis personas expertas en materias de educación y comunicación. A continuación se describe el proceso llevado a cabo y se revelan los resultados del análisis del juicio de expertos apelando al grado de pertinencia de los ítems que componen el cuestionario. En primer lugar, se creó una guía para la evaluación del cuestionario por parte de expertos. En ella se presentaron los diferentes objetivos del cuestionario con sus respectivos indicadores e ítems solicitando a los expertos que indicasen el grado de pertinencia en una escala de 1 a 4 puntos. Los resultados obtenidos a partir de esta evaluación se presentan a continuación (Véase Tabla 6). 
18 | Patricia de-Casas-Moreno, Pablo Maraver-López e Ignacio Aguaded ARTíCULOS DE INVESTIGACIÓN

\begin{tabular}{|l|c|c|}
\hline Dimensiones/preguntas & Preguntas cerradas & Likert de grado de acuerdo \\
\hline Dimensión 1 & $100 \%$ & $90.8 \%$ \\
\hline Dimensión 2 & $94 \%$ & $87.9 \%$ \\
\hline Dimensión 3 & - & $97.9 \%$ \\
\hline Dimensión 4 & - & $99.4 \%$ \\
\hline
\end{tabular}

Tabla 6: Grado de pertinencia de los ítems según expertos

Tras observar la tabla, es necesario indicar que las dimensiones 1 y 2 tienen preguntas cerradas asociadas a la escala tipo Likert, mientras que las dimensiones 3 y 4 solo cuentan con ítems tipo Likert de grado de acuerdo. A la vista de los resultados obtenidos, los ítems muestran un alto grado de pertinencia con valores que rondan el $90 \%$, evidenciando de este modo la validez de contenido del instrumento. Debido a la ausencia de una muestra amplia para poder ofrecer otras evidencias de validez, las nuevas aplicaciones que se realicen del cuestionario sobre una muestra más amplia de sujetos aportarán evidencias de validez del cuestionario complementarias.

\section{Discusión}

El papel de la televisión en esta investigación soporta una carga muy alta en contenido sentimental y emotivo, relacionado con las figuras de los personajes famosos de la crónica social de actualidad y los estereotipos que se conforman alrededor de ellos. Muchas son las investigaciones que han estudiado y verificado la influencia de este medio de masas en los hábitos de conducta de los espectadores (Gila \& Guil, 1999: 90-91; Marín, 2012: 194-195). En este sentido, partimos del punto en común por el gusto de la audiencia sobre las vidas ajenas e íntimas de las figuras populares y el mundo del glamour, encargadas de generar y transformar las pautas de conductas y las percepciones críticas muy alejadas de la realidad objetiva. La televisión, a pesar de ser el medio social por excelencia, no se usa de manera educativa, sino más bien, como forma de entretenimiento y como herramienta para captar la máxima audiencia posible. 
Es necesario destacar que, los estereotipos que hemos encontrado durante el visionado de las piezas informativas y el análisis de contenido que hemos elaborado son estrictos, alejándose de las críticas malintencionadas sobre los personajes famosos. Asimismo, hemos podido observar el punto de convergencia que se crea con las múltiples informaciones transmitidas sobre una sola persona. Además, estos estereotipos cumplen una función muy importante y es la subordinación de los grupos consiguiendo el famoso posicionarse frente al individuo como una figura dominante. Esta afirmación ha sido apuntada anteriormente por Amossy \& Herschberg (2010: 43), quien además, indica que el estereotipo se convierte en un instrumento generador de tensión entre las relaciones interpersonales en el momento del visionado audiovisual, concibiendo prejuicios frente a los famosos o aquellas personas que actúen como ellos.

Por otro lado, tras realizar el análisis pertinente según los indicadores establecidos: clase social, procedencia, sexo y edad; hemos observado los múltiples juicios que se elaboran sobre aquellos personajes populares. También, hemos comprobado la fuerte presencia femenina dentro del programa analizado. Las noticias sobre mujeres jóvenes entre 20 a 40 años, de clase social media y con nacionalidad española, marcan el ritmo del programa "Corazón», ya que son las encargadas de generar historias relevantes en la crónica social rosa con relatos románticos, de pasarela 0 de embarazos. Además, la carrera profesional de los protagonistas es un indicador muy relevante, pues son los meritócratas quienes mantienen una posición elevada entre los personajes visionados. De esta manera, los resultados que hemos obtenido son que el $68 \%$ de la clase social están compuestos por la clase media, un $82.28 \%$ meritócratas, $75 \%$ de procedencia nacional y un $72 \%$ de personas comprendidas entre 20 a 40 años como ya citábamos anteriormente.

En este sentido, es necesario retomar la idea principal de que este tipo de programas tienden a generar pautas y valores de conductas alejados de la realidad, enfatizando las consecuencias negativas que pueden provocar en la audiencia como por ejemplo los cambios sociales o la falta de actitud crítica debido a la constante manipulación informativa que se produce. Sin duda, como apunta San Miguel, et al. (2012: 194) son los espectadores quienes dotan a las imágenes de significado y podemos verlo bien reflejado en las noticias ofrecidas por el programa «Corazón», 


\section{ARTÍCULOS DE INVESTIGACIÓN}

que ofrecen información de actualidad y magnética para los espectadores con el fin de interpretar el mensaje y crear a su vez una conciencia crítica sobre él. Por lo tanto, es ineludible como anota Belmonte \& Guillamón (2008: 115) conseguir llevar a cabo una correcta alfabetización audiovisual para que los espectadores consigan comprender qué es la realidad y qué es un espejismo de ésta.

Es indiscutible resaltar que la televisión perjudica a la sociedad a través de la creación de la opinión pública. En este sentido, es necesario indagar en la competencia mediática de los espectadores debido a la infoxicación y desinformación de los programas basados en la crónica rosa con el fin de ofrecer información de mejor calidad. Además, es necesario realizar un estudio socio-demográfico sobre las condiciones sociales del individuo para atender sus necesidades tal y como hemos apuntado en la construcción del cuestionario. Por lo tanto, tal y como han indicado otros estudiosos anteriormente (Katz \& Blumler, 1974; Fleur \& Ball-Rokeach, 1982; Tourine 1993; Kubey \& Csikszentmihalyi, 2013) es obligatorio diferenciar información de entretenimiento y comprender la influencia de la televisión en los hábitos de conducta de la audiencia.

Por otro lado, en relación a la creación y validación del instrumento que se ha presentado en este estudio, podemos señalar que a raíz de los resultados obtenidos en el análisis del cuestionario que, junto a la alta consistencia interna del test (Alpha de Cronbach), indica que en la muestra de nuestro estudio, el cuestionario parece medir un solo constructo con distintos factores intercorrelacionados. Además, los resultados del juicio de expertos evidencian una considerable validez de contenido del instrumento. En suma, el cuestionario parece tener unas buenas propiedades psicométricas como instrumento de evaluación de los hábitos de la audiencia.

Para concluir, podemos indicar que esta investigación es el punto de partida de otros estudios más amplios relacionados con los estereotipos y hábitos de la audiencia frente al consumo de los programas de carácter sensacionalista, en especial los relacionados con la crónica rosa. Además, es necesario ahondar mucho más en la materia debido a la constante demanda educativa por generar estrategias que consigan formar a televidentes más cualificados en una televisión de calidad. 


\section{Referencias}

Acaso, M. (2006). Esto no son las torres gemelas. Cómo aprender a leer la televisión y otras imágenes. Madrid: Catarata.

Amossy, R., \& Herschberg, A. (2010). Estereotipos y clichés. Argentina: Eudeba.

Belmonte, J., \& Guillamón, S. (2008). Co-Educar la mirada contra los estereotipos de género en Tv. Comunicar, 31 (16), 115-120. D0I: http://dx.doi.org/10.3916/ c31-2008-01-014

Berger, P.L. \& Luckmann, T. (2003). La construcción social de la realidad. Buenos Aires: Amorrortu.

Brown-Givens, S. M. y Monahan, J. L. (2005). Priming mammies, jezebels, and other controlling images: An examination of the influence of mediated stereotypes on perceptions of an African American woman. Media Psychology, 7. DOI: 10.1207/S1532785XMEP0701_5

Cáceres, M.D. (2012). Telerrealidad y aprendizaje social. Revista ICON014. Revista científica de Comunicación y Tecnologías emergentes, 5(1), 123-144. DOI: http://dx.doi.org/10.7195/ri14.v5i1.375.

Camacho, R. (2006). El ajuste de las cuentas en el sector audiovisual: Teoría y práctica de la nueva televisión en España. Sevilla: Instituto Andaluz de Administración Pública.

Debord, G. (1976). La sociedad del espectáculo. Madrid: Castellote.

Eco, U. (1986). La estrategia de la ilusión. Barcelona: Lumen.

Ferrés, J. (1997). La televisión subliminal. Barcelona: Paidós.

Fleur, M.L., \& Ball-Rokeach, S. (1982). Theories of Mass Communication. New York: Longman.

Fuente, C., Martínez, J.M. \& Del-Prado, R. (2014). Las audiencias activas en la regulación de los medios: la dialéctica consumidor-ciudadano en España y México [Active Audiences in the Regulation of the Audiovisual Media. Consumer versus Citizen in Spain and Mexico]. Comunicar, 43, 91-99. D0I: http://dx.doi. org/10.3916/C43-2014-09

Galán-Fajardo, E. (2006). Personajes, estereotipos y representaciones sociales. Una propuesta de estudio y análisis de la ficción televisiva. Eco-Pos, 9 (1), 58-81.

Gila, J., \& Guil, A. (1999). La mujer actual en los medios. Estereotipos cinematográficos. Comunicar, 12, 89-93. 


\section{ARTÍCULOS DE INVESTIGACIÓN}

Gilovich, T. (1993). How We Know What Isn't So. New York: The Free Press.

González, I.J.G., \& Leal, I.J.G. (2010). Análisis de contenido de los estereotipos presentes en «the big bang theory». Razón y Palabra, (72).

González-Requena, J. (1985). Introducción a una teoría del espectáculo. Revista Telos, 4. 33-44.

González-Requena, J. (1989). El espectáculo informativo: o la amenaza de lo real. Madrid: Cátedra.

Gordillo, I. (2009). Manual de narrativa televisiva. Madrid: Síntesis.

Imbert, G. (2003). El zoo visual: de la televisión espectacular a la televisión especular. Barcelona: Gedisa.

Imbert, G. (2004). De lo espectacular a lo espectacular: apostilla a la sociedad del espectáculo. Cuadernos de Información y Comunicación, 9, 69-81.

Imbert, G. (2008). El transformismo televisivo. Postelevisión e imaginarios sociales. Madrid: Cátedra.

Katz, E., \& Blumler, J.G. (1974). The uses of mass communications. Current Perspectives on Gratifications Research. Sage Annual Reviews of Communication Research, Beverly Hills.

Kubey, R., \& Csikszentmihalyi, M. (2013). Television and the quality of life: How viewing shapes everyday experience. Routledge.

Lee, A.Y.L. (2010). Media Education: Definitions, Approaches and Development around the Globe. New Horizons in Education, 58 (3), 1-13.

Lee, A. \& So, C. (2014). Alfabetización mediática y alfabetización informacional: similitudes y diferencias [Media Literacy and Information Literacy: Similarities and Differences]. Comunicar, 42, 137-146. D0I: http://dx.doi.org/10.3916/ C42-2014-13

March, J.C., \& Prieto, M.A. (2006). Análisis de la televisión en la «Generación TV». Madrid: Red Comunicar.

Marín, A.L. (Ed.) (2012). La nueva comunicación. Madrid: Trotta.

NAMLE (2010). Media Literacy Defined. National Association for Media Literacy Education. (http://namle.net/publications/media-literacy-definitions).

Núñez, S. (2005). Género y televisión. Estereotipos y mecanismos de poder en el medio televisivo. Comunicar, 25, 301-302.

Romero-Rodríguez, L.M. (2014). Pragmática de la desinformación. Estratagemas $e$ incidencia de la calidad informativa de los medios. Huelva: Repositorio 
Institucional Arias Montano.

Romero-Rodríguez, L.M., De Casas Moreno, P. \& Torres Toukoumidis, A. (2015). Estereotipos, tópicos y lenguaje de la programación sensacionalista en la televisión: programa «Corazón» de TVE. Alteridad, 10(1), 31-43.

San Miguel, B.G., Fidalgo, M.R., \& Santos, C.G. (2012). La construcción sexista de la imagen en los medios televisivos. Revista ICON014. Revista científica de Comunicación y Tecnologías emergentes, 7(3), 191-209. D0I: http://dx.doi. org/10.7195/ri14.v7i3.312

Sartori, G. (2012). Homo videns: la sociedad teledirigida. Madrid: Taurus.

Searle, J.R. (1997). La construcción de la realidad social. Barcelona: Paidós.

Soler, M. (2005). El Informe del «Comité de sabios»: bases para una televisión de calidad. Comunicar, 25, 309.

Talavera, M.D.M.L., \& Bermejo, J.B. (2007). Telebasura, ética y derecho: límites a la información de sociedad en televisión. En La ética y el derecho de la información en los tiempos del postperiodismo, 307-324. Valencia: Fundación COSO de la Comunidad Valenciana para el Desarrollo de la Comunicación y la Sociedad. Vargas-Llosa, M. (2009). La civilización del espectáculo. Letras Libres, 89, 6-14. 